\section{Homeopathy and its ethical use in dentistry}

S. Eames ${ }^{1}$ and P. Darby ${ }^{2}$

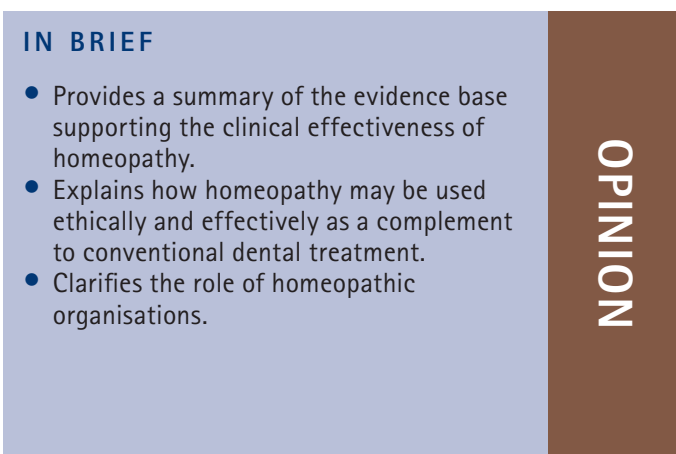

Media coverage of homeopathy over the past few years has tended to concentrate on the very negative position taken by sceptics, while the possible benefits of homeopathy are ignored. This has resulted in coverage that has been rather onesided, inaccurate and at times hysterical. A perfect example is Dr David Shaw's opinion piece 'Unethical aspects of homeopathic dentistry' (Br DentJ 2010; 209: 493-496) which falls far short of providing a basis for balanced intellectual discussion. The authors are therefore grateful to the $B D J$ for the opportunity to outline the case for integrating homeopathy in dental practice.

\section{THE POLITICS OF HOMEOPATHY}

Significant adverse publicity was generated by last year's report on homeopathy by The House of Commons Science and Technology Committee, which concluded that there was no evidence base for homeopathy and it therefore should not be funded by the NHS. However, far less publicity has been given to the fact that this report and its conclusions have been widely criticised and that the government rejected its recommendations. Indeed, during the hearings the Minister for Health Services said that government should not stop NHS funding for homeopathy and it would be illiberal to do so. ${ }^{1}$

Furthermore, it is not widely known that this report was formalised by only four MPs. One is a high-profile and vitriolic opponent of homeopathy, who actually took part in public demonstrations against homeopathy during the production of the report. Two other authors were new appointees to the committee and did not attend the oral hearings. The fourth MP voted against the report as he felt the process was unfair. ${ }^{2}$

It is astonishing that such effort is devoted to the criticism of homeopathy

'President, ${ }^{2}$ Dental Dean, Faculty of Homeopathy, Hahnemann House, 29 Park Street West, Luton, LU1 3BE

Correspondence to: Dr Peter Darby

Email: pdarby@FacultyofHomeopathy.org

Accepted 22 February 2011

DOI: 10.1038/sj.bdj.2011.237

${ }^{\circledR}$ British Dental Journal 2011; 210: 299-301 when it is a tried and tested treatment recording high patient satisfaction and low incidence of side-effects, is relatively inexpensive, and has a growing evidence base. Our healthcare system is under extreme financial pressure, so to discourage a therapy with all these advantages and that promotes individual responsibility for healthcare and lifestyle appears to contradict our aims as a society.

\section{HOMEOPATHY - THE EVIDENCE}

Homeopathy is a system of medicine that is based on the principle of 'like cures like', which has been used for over 200 years. The medicines used can be in both lowand ultra-molecular dilution but both clinical experience and evidence suggest that they are still effective.

These medicines have been available for such a long time they cannot be patented. Consequently, there is no commercial advantage in funding research for the drug companies and as a result investment in controlled clinical trials is minimal.

The constant attacks on homeopathy over the past few years have managed virtually to obscure the positive research evidence. There have been well over 100 randomised controlled trials (RCTs) in homeopathy and far more are positive than negative. ${ }^{3}$ There have also been a series of meta-analyses of these trials and the majority of these have been positive. It is interesting to note, however, that the negative results from the last meta-analysis were published in The Lancet $^{4}$ and quickly adopted by sceptics as incontrovertible evidence of the inefficacy of homeopathy. This is despite the fact the analysis was based only on a small subset of the studies and that it has subsequently been widely criticised ${ }^{5,6}$ for not conforming to many of the QUOROM guidelines for high quality meta-analysis design and reporting. Indeed, when the overall results of the homeopathic trials were compared with conventional trials for similar conditions there was no significant difference found. The results displayed as funnel plots in Figure 1 illustrate this point. ${ }^{4}$

The scientific study of ultra-molecular dilutions is in its infancy, and currently there is no complete explanation of how the medicines work. Nevertheless, as well as the RCT evidence highlighted above, there is a growing body of evidence that suggests ultra-molecular solutions can be physiologically active. ${ }^{7}$ It is thus rather unscientific and premature to suggest that homeopathic medicines cannot work. In addition to the RCT evidence, there is also a wealth of case histories and outcome studies suggesting consistent and positive results from the use of homeopathic medicines. ${ }^{8}$

\section{USES OF HOMEOPATHY WITHIN DENTISTRY}

Dentists use homeopathic medicines in everyday practise as an adjunct to 
conventional treatment. The inclusion of homeopathic medicine in a dentist's therapeutic armoury is particularly useful for a range of treatments, from relatively mild acute conditions through to complex chronic pathologies. Some of these conditions have historically been shown to be difficult to treat or manage: for example, dental anxiety, atypical facial pain, burning mouth syndrome and post-extraction osteitis. Success has also been achieved in the treatment of chronic conditions where conventional treatments have failed or are contra-indicated and which include the management of lichen planus and recurrent infection.

Homeopathy is not a replacement or alternative to good clinical dental care but is used alongside conventional treatments and drug regimens. Dr Shaw's article seems to imply that homeopathic dentists are not providing their patients with conventional dental care and that they have a different agenda and ethos in their approach to treating patients. This is not the case: the ethical treatment of any patient is paramount for all homeopathic clinicians, be they medical or dental. Healthcare professionals trained in the use of homeopathy know it works and prescribe appropriately, just as with any other prescription. To state that any form of deception is involved is defamatory.

\section{THE PLACEBO EFFECT}

It has been claimed that any positive outcome experienced by patients receiving homeopathic treatment is only as a result of a placebo effect. This is despite the overall positive results from RCT studies suggesting an effect over and above that of placebo. ${ }^{9}$ It should be highlighted that all treatments have a placebo component and, rather than dismissing it as irrelevant and 'unethical', we should be discussing how to maximise it for the benefit of our patients.

Dr Shaw appears muddled on the issue of placebos. He states, 'for the placebo effect to occur, patients must believe that they are receiving treatment that is better than placebo ... they must be deceived ... in order to receive the paltry benefit that homeopathy might offer'. Yet he also says, 'prescribing simple placebos ethically may be possible in some situations. ${ }^{10}$

\section{SCIENCE, KNOWLEDGE, EXPERIENCE AND ETHICS}

Dr Shaw appears to view the practise of medicine in rather black and white terms and implies that if a treatment has performed well in RCTs, everyone can be assisted by this treatment. All thoughtful healthcare professionals are aware that a positive RCT merely means that a certain percentage of their patients might be helped more by a particular treatment; but what about those who suffer an adverse reaction from that particular treatment? Real patients, their illnesses and their treatments are so much more complicated than any RCT can consider. In fact, according to the $B M J, 51 \%$ of treatments have unknown effectiveness (Fig. 2). ${ }^{11}$

In his paper Dr Shaw also states that if a homeopathic treatment fails and the patient then seeks conventional treatment, they have been 'harmed.. ${ }^{10}$ This statement is ludicrous. Such a statement could apply to any intervention that fails to help the patient. Let us not forget that iatrogenic disease is the fifth largest cause of death in the US. ${ }^{12}$ It behoves us all as responsible practitioners to minimise the amount of potentially dangerous medication used and homeopathy can be a vital part of this approach. A health professional with additional training in homeopathy is ideally placed to select the most appropriate treatment, give responsible advice and change the treatment model when required. This does not include the need to deceive patients as Dr Shaw claims.

Applying this approach over many years in practice, the authors have seen significant positive results in many patients prescribed homeopathy where appropriate, and indeed they personally would feel it unethical not to suggest something that might be useful, especially when all other medical intervention has failed.

\section{THE ROLE OF HOMEOPATHIC ORGANISATIONS}

A significant part of Dr Shaw's article is devoted to a largely incorrect account of the role of various organisations and the contents of their websites.

The Faculty of Homeopathy was incorporated by an Act of Parliament in 1950 and is a register of statutorily registered health professionals, including dentists, who have successfully completed Faculty

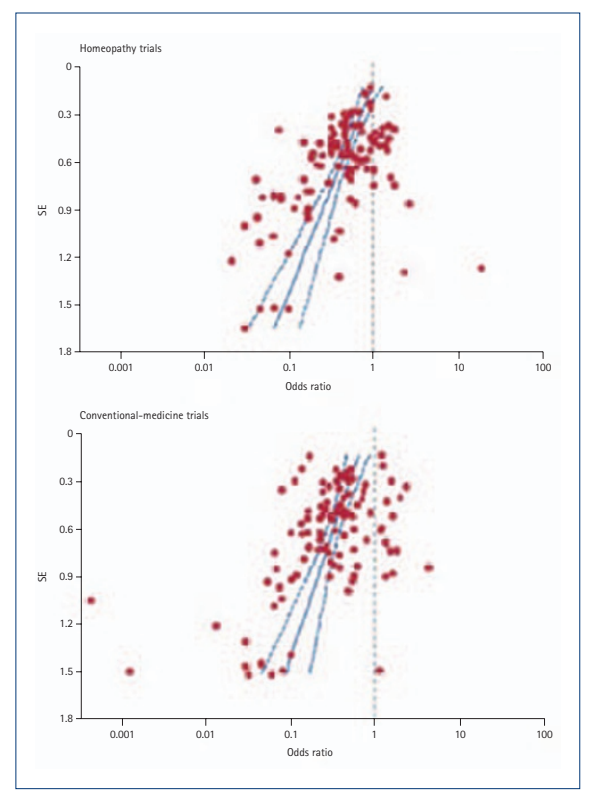

Fig. 1 Funnel plot of 110 homeopathy trials and $\mathbf{1 1 0}$ matched conventional-medicine trials. Solid lines indicate predicted treatment effects from meta-regression, with dotted lines representing the $95 \% \mathrm{Cl}$. Reproduced from reference 4, Copyright (2005), with permission from Elsevier

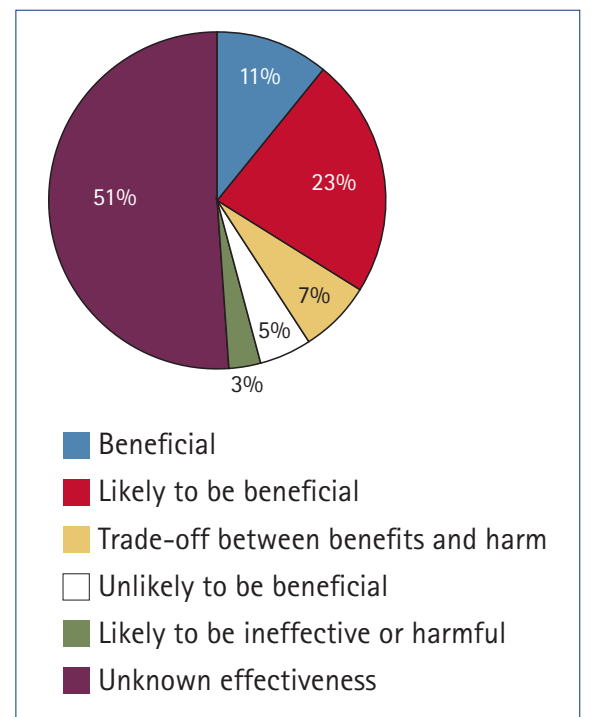

Fig. 2 Percentage of treatments falling into different categories of effectiveness. Reproduced from reference 11 with permission from BMJ Clinical Evidence

of Homeopathy accredited training and exams. Faculty dentists will have been taught and examined on how to combine homeopathy responsibly within their individual professional setting. Faculty members are bound by the professional code of their respective profession - ergo dentists must work to the professional code of ethics set by the GDC. Registration with their statutory body is a requirement for retained membership of the Faculty of Homeopathy. 
The quotation in Dr Shaw's paper that notes 'advice to the public' on the Faculty's website is actually taken from the education section of the website and quotes part of the dental curriculum. The information is clearly not intended as advice to the public, as Shaw states.

The British Homeopathic Association is a charity devoted to gaining greater access to homeopathy for patients. It is not a register or training body and that is very clear from its website. It feels that the best providers of homeopathy are healthcare professionals such as doctors and dentists. It is a charity supported by those who have benefitted from homeopathic treatment and who wish to help others find relief in the same way.

The Society of Homeopaths has no specific role in homeopathic dentistry. It is a registering body for those who are not statutorily regulated healthcare professionals, but individuals who have undertaken quality-assured homeopathic training that meets national occupational standards for homeopaths.

The British Homeopathic Dental Association is a membership organisation for dentists who have trained in homeopathy and endorses postgraduate training and education in homeopathic medicine.

1. House of Commons Science and Technology Committee. Evidence check 2: homeopathy. Fourth report of session 2009-10. http://www. publications.parliament.uk/pa/cm200910/cmselect/ cmsctech/45/4502.htm (accessed 14 March 2011).

2. House of Commons Science and Technology Committee. Evidence check 2: homeopathy. Fourth report of session 2009-10. Formal minutes. http:// www.publications.parliament.uk/pa/cm200910/ cmselect/cmsctech/45/4508.htm laccessed 14 March 2011).

3. Faculty of Homeopathy. Randomised controlled trials in homeopathy webpage. http://www.facultyofhomeopathy.org/research/rcts in homeopathy/ (accessed 14 March 2011).

4. Shang A, Huwiler-Müntener K, Nartey L et al. Are the clinical effects of homoeopathy placebo effects? Comparative study of placebo-controlled trials of homoeopathy and allopathy. Lancet 2005; 366: 726-732.

5. Linde K Jonas W. Correspondence: Are the clinical effects of homoeopathy placebo effects? Lancet 2005; 366: 2081-2082.

6. Lüdtke R, Rutten A L B. The conclusions on the effectiveness of homeopathy highly depend on the set of analyzed trials. J Clin Epidemio/ 2008; 61: 1197-1204.

7. House of Commons Science and Technology Committee. Evidence check 2: homeopathy. Fourth report of session 2009-10. Memorandum submitted by Dr Peter Fisher HO 21. Homeopathy: the evidence from basic research. http://www.publications. parliament.uk/pa/cm200910/cmselect/cmsctech/ memo/homeopathy/ucm 2102.htm (accessed 14 March 2011).

8. Faculty of Homeopathy. Clinical outcomes studies webpage. http://www.facultyofhomeopathy.org/ research/clinical_outcomes_studies.html (accessed 14 March 2011).

9. Linde $\mathrm{K}$ Clausius N, Ramirez $\mathrm{G}$ et al. Are the clinical benefits of homoeopathy placebo effects? A metaanalysis of placebo-controlled trials. Lancet 1997; 350: 834-843.

10. Shaw D. Unethical aspects of homeopathic dentistry. Br Dent J 2010; 209: 493-496.

11. BMJ Clinical Evidence. How much do we know? http://clinicalevidence.bmj.com/ceweb/about/ knowledge.jsp (accessed 18 January 2011).

12. Lazarou J, Pomeranz B H, Corey P N. Incidence of adverse drug reactions in hospitalized patients: a meta-analysis of prospective studies. JAMA 1998; 279: 1200-1205. 